\title{
Role of the Nlrp3 inflammasome in microbial infection
}

\author{
Paras K. Anand, R. K. Subbarao Malireddi andThirumala-Devi Kanneganti*
}

Department of Immunology, St Jude Children's Research Hospital, Memphis, TN, USA

\section{Edited by:}

Amal Amer, The Ohio State University, USA

\section{Reviewed by:}

Amal Amer, The Ohio State University, USA

Kevin Coombs, University of Manitoba, Canada

\section{*Correspondence:}

Thirumala-Devi Kanneganti,

Department of Immunology, St Jude

Children's Research Hospital,

Memphis, TN 38105, USA.

e-mail: thirumala-devi.kanneganti@

stjude.org
The intracellular Nod-like receptor Nlrp3 has emerged as the most versatile innate immune receptor because of its broad specificity in mediating immune response to a wide range of microbial or danger signals. Nirp3 mediates assembly of the inflammasome complex in the presence of microbial components leading to the activation of caspase- 1 and the processing and release of the pro-inflammatory cytokines IL-1 $\beta$ and IL-18. In this review, we give an update on the recent literature examining the role of NIrp3 inflammasome in response to fungal, bacterial, and viral infections.

Keywords: NLR, NIrp3, inflammasome, caspase-1, IL-1ß, IL-18

\section{INTRODUCTION}

The innate immune system depends on germline encoded pattern recognition receptors (PRRs) for the detection of various microbial components. PRRs belong to different classes of receptors such as toll-like receptors (TLRs) that are localized at the cell surface or in endosomes and the cytosolic RIG-I-like receptors (RLRs), Nodlike receptors (NLRs), and the recently identified HIN-200 family members (Palsson-McDermott and O'Neill, 2007; Hornung and Latz, 2010; Unterholzner et al., 2010). Upon perceiving a microbial or danger stimuli, these receptors activate downstream signaling events leading to generation of the appropriate immune response (Creagh and O'Neill, 2006). Inflammasomes are molecular platforms that assemble by hetero-oligomerization of a nucleotidebinding oligomerization domain, LRR containing receptor (NLR), an adaptor protein ASC and pro-caspase-1, and triggers caspase-1 activation and downstream maturation and secretion of the proinflammatory cytokines IL-1 $\beta$ and IL-18 (Kanneganti et al., 2006a, 2007; Lamkanfi and Kanneganti, 2010).

The requirement for a particular NLR within the inflammasome complex depends upon the upstream trigger. The Nlrp3 inflammasome, for example, acts as a global sensor that responds to a wide array of stimuli whereas Nlrc4 and Nlrp1 inflammasomes are more specific; they are activated only by bacterial flagellin and anthrax toxin, respectively (Boyden and Dietrich, 2006; Franchi et al., 2006; Miao et al., 2006). Many studies have now uncovered the crucial role of the Nlrp3 inflammasome in different microbial infections. The purpose of this review is to give an update on the recent literature highlighting the role of Nlrp3 inflammasome during host responses to various pathogens.

\section{FUNGAL INFECTION}

Most of the fungi are non-pathogenic in healthy individuals; however, they are long known to cause severe systemic and superficial infections in patients with AIDS, cancer or other immunocompromised conditions (Romani, 2004). Although the antifungal effects of IL-1 $\beta$ and IL-18 were known previously (Mencacci et al., 2000;
Vonk et al., 2006), the inflammasome dependent processing of these cytokines was not addressed in those studies. One report suggested that caspase- 1 is constitutively active in human monocytes and does not require inflammasome assembly for its activation (van de Veerdonk et al., 2009). In contrast, other reports in mouse models established the inflammasome dependent caspase- 1 activation and IL- $1 \beta$ production in response to pathogen-associated molecular patterns from Candida albicans, Aspergillus fumigatus, and Saccharomyces cerevisiae (Gross et al., 2009; Hise et al., 2009; Joly et al., 2009; Kumar et al., 2009; Lamkanfi et al., 2009; Kankkunen et al., 2010; Poeck and Ruland, 2010; Said-Sadier et al., 2010). Intriguingly, mice deficient in Nlrp3 are hyper-susceptible to C. albicans in several infection models (Gross et al., 2009; Hise et al., 2009; Joly et al., 2009). However, the in vivo role of Asc and caspase-1 in C. albicans infection is not known. Interestingly, hyphael stages of these heteromorphic fungi are more virulent and are suggested to be more aggressive inducers of inflammation (Lo et al., 1997). Indeed, yeast forms of A. fumigatus and C. albicans either did not induce or showed poor Nlrp3 inflammasome activation, respectively providing evidence for the differential regulation of immune responses based on the morphological forms of fungi (Hise et al., 2009; Joly et al., 2009; Said-Sadier et al., 2010). Accordingly, appearance of hyphael forms of fungi is a positive prognosis factor for the rapidly spreading fungal infections in affected tissues and organs.

The Dectin-CARD9 signaling pathway through syk kinase regulates transcriptional up-regulation of cytokines downstream of fungal recognition (Gross et al., 2009; Poeck and Ruland, 2010). Interestingly, inhibition of syk kinase, either pharmacologically or through shRNA-based knock down, resulted not only in the inhibition of transcription but also reduced the Nlrp3 inflammasome activation (Gross et al., 2006; Said-Sadier et al., 2010). These observations thus suggest that the syk kinase signaling may contribute to the Nlrp3 inflammasome activation by providing the necessary signals required either for its up-regulation at the transcriptional level and/or for its assembly by a yet unidentified mechanism. 


\section{BACTERIAL INFECTION}

Nlrp3 inflammasome has been shown to be particularly important in response to several bacterial pathogens. Staphylococcus aureus induced IL-1 $\beta$ secretion, for example, requires Nlrp3 inflammasome activation (Mariathasan et al., 2006; Craven et al., 2009). By using purified $\alpha$-hemolysin Craven et al. (2009) discovered a crucial role for Staphylococcus aureus hemolysins in Nlrp3 inflammasome activation in THP-1 monocytes. However, Mariathasan et al. (2006) reported no role for Staphylococcus aureus hemolysins $(\alpha-$, $\beta$-, or $\gamma$-hemolysins) in the induction of Nlrp3 inflammasome in bone marrow-derived macrophages by using Staphylococcus aureus hemolysin mutants. The differences observed between these two studies might be due to differences in the cell types used or to the fact that other redundant factors released by Staphylococcus aureus hemolysin mutants activate Nlrp3 as efficiently.

Salmonella typhimurium is a flagellated bacterium that has been shown to activate the Nlrc4 inflammasome (Franchi et al., 2006; Miao et al., 2006). However, Broz et al. (2010) recently reported activation of both the Nlrc4 and Nlrp3 inflammasomes via SPI-1 and SPI-2 dependent mechanisms. Unlike previous studies, which had focused on the SPI-1-dependent mechanism of caspase-1 activation that occurs rapidly and activates Nlrc4, this study focused on Salmonella SPI-2 dependent mechanisms that activate the Nlrp3 inflammasome. During Salmonella infection, Nlrp3 inflammasome dependent IL-1 $\beta$ production was observed between 17 and $20 \mathrm{~h}$ after infection. Interestingly, both Nlrp3 and Nlrc4 were recruited into a single ASC focus in response to Salmonella that correlated well with the amount of IL- $1 \beta$ and IL- 18 released (Broz et al., 2010). Accordingly, mice lacking both of these NLRs were found more susceptible to infection than mice deficient in either Nlrc4 or Nlrp3 alone (Broz et al., 2010). However, the role of Nlrp3 in Salmonella infection needs further verification. Nonetheless, these observations indicate redundant roles for inflammasomes during infection.

The redundant nature of the inflammasomes is also evident during Listeria infection. Listeria monocytogenes activates inflammasome in an Nlrp3-dependent manner (Mariathasan et al., 2006). However, recent studies also show the activation of Nlrc4 and Aim2 inflammasomes upon Listeria infection (Warren et al., 2008; Wu et al., 2010). In particular, Nlrp3 inflammasome is activated in response to phagosomal membrane damage caused by expression of listeriolysin O (LLO) by Listeria (Wu et al., 2010). Indeed, membrane damage resulting in cathepsin $B$ release has been shown previously to result in Nlrp3 activation (Hornung et al., 2008). Critical role for the Nlrp3 inflammasome has also been reported during Mycobacterium infection (Carlsson et al., 2010; McElvania Tekippe et al., 2010). Ascdeficient mice were found to be more susceptible to M. tuberculosis infection because of defective granuloma formation in these mice (McElvania Tekippe et al., 2010). In contrast, another study reported similar M. marinum burden in WT and Asc-deficient mice (Carlsson et al., 2010). Notably, the two studies differ in the Mycobacterium spp. examined and the route of the infection.

The role of Nlrp3 inflammasome in other bacterial infections has also been studied. Streptococcus pyogenes activates the Nlrp3 inflammasome in a streptolysin O (SLO) dependent manner (Harder et al., 2009). Nlrp3 was essential for IL-1 $\beta$ production but the mutant mice were equally susceptible to Streptococcus pyogenes infection as wild-type mice (Harder et al., 2009). Vibrio spp. also induced Nlrp3 inflammasome activation mediated by hemolysins and toxins (Toma et al., 2010). Staphylococcus aureus activated Nlrp3 inflammasome dependent on hemolysins and bacterial lipoproteins secreted in culture supernatants (Munoz-Planillo et al., 2009). Similarly, Neisseria gonorrhoeae induced IL-1 $\beta$ production via Nlrp3 inflammasome that was dependent upon the secreted virulence factor lipo-oligosaccharide (Duncan et al., 2009).

\section{VIRAL INFECTION}

Within mammalian hosts, viruses are recognized by TLR3 and TLR7 in the endosomes and by RIG-I in the cytoplasm mounting robust immune responses through the regulation of type-1 interferons (Ichinohe et al., 2009; Kanneganti, 2010). Initial evidence implicating Nlrp3 inflammasome in viral infection came from reports of caspase- 1 activation and production of IL- $1 \beta$ and IL-18 during Sendai virus and influenza virus infections (Kanneganti et al., 2006b). Infection with the modified vaccinia virus Ankara also activates the Nlrp3 inflammasome (Delaloye et al., 2009). Several lines of evidence indicate that the Nlrp3 inflammasome might detect the presence of viral RNA and DNA in intracellular compartments. For example, Nlrp3 has been implicated in the detection of viral DNA from adenovirus in cell culture (Muruve et al., 2008). Additionally, transfection of human or mouse cell lines with ssRNA or dsRNA analogs, such as polyinosinic-polycytidylic acid (poly(I:C)), is sufficient to activate Nlrp3 (Allen et al., 2009). In vivo administration of poly(I:C) or the purified ssRNA of influenza A virus to mice also led to IL- $1 \beta$ secretion and inflammation due to Nlrp3 activation (Kanneganti et al., 2006b; Allen et al., 2009; Thomas et al., 2009).

Several recent studies reported activation of the Nlrp3 inflammasome in response to influenza A virus in mouse bone marrowderived macrophages, dendritic cells, monocytic THP-1 cells and in vivo (Allen et al., 2009; Ichinohe et al., 2009; Thomas et al., 2009). Perhaps, the Nlrp3 inflammasome activation in response to viruses has been best characterized by using influenza A virus. Influenza A virus infection led to reduced production of cytokines and chemokines in mice lacking components of the Nlrp3 inflammasome leading to decreased recruitment of neutrophils and monocytes (Allen et al., 2009; Thomas et al., 2009). This was accompanied by epithelial necrosis and collagen deposition, an effect that was more severe in the bronchia of the Nlrp3 mutant mice. Despite these facts, Nlrp3 inflammasome had no role in either virus control or generation of adaptive immunity (Thomas et al., 2009). In contrast, another study reported importance of the Nlrp3 in viral clearance (Allen et al., 2009). The apparent discrepancy might be due to different doses of infection or evaluation of viral plaqueforming units at different days after infection. Still another study by Ichinohe et al. (2009), however, reported a role for Nlrp3 only in certain cell types, but observed no role for it in the generation of adaptive immune responses similar to the study by Thomas et al. (2009). Interestingly, Ichinohe et al. (2010) proposed a role for the viral M2 ion channel in transporting $\mathrm{H}^{+}$out of the trans-Golgi network. The authors postulated that this perturbation somehow activates other plasma membrane channels responsible for $\mathrm{K}^{+}$efflux thus activating the Nlrp3 inflammasome (Ichinohe et al., 2010; Kanneganti, 2010). 


\section{MECHANISMS OF INFLAMMASOME ACTIVATION}

The Nlrp3 inflammasome is generally believed to require a twosignal mechanism. Stimulation with LPS leads to TLR activation resulting in synthesis of precursor forms of the cytokines IL-1 $\beta$ and IL-18. Further stimulation of these cells with ATP activates P2X7R, allowing $\mathrm{K}^{+}$efflux through membrane pores that results in Nlrp3 inflammasome activation. Recent reports have proposed that besides transcriptional up-regulation of IL- $1 \beta$ and IL-18, LPS also leads to up-regulation of Nlrp3 expression in an NF- $\mathrm{KB}$ dependent manner (Bauernfeind et al., 2009; Franchi et al., 2009). However, a recent study reported that infection with $V$. cholerae did not up-regulate Nlrp3 expression suggesting that it is not indispensable for caspase-1 activation, at least in Vibrio infection (Toma et al., 2010).

Many pathogens bypass the necessary second signal (i.e., P2X7R activation) required for inflammasome activation through the formation of membrane pores. Streptococcus pyogenes, for example, activates Nlrp3 inflammasome in a P2X7R-independent manner (Harder et al., 2009). Streptococcus pyogenes synthesizes the poreforming toxin SLO which may therefore provide the necessary functions of ATP and, as has been proposed before allows the delivery of microbial molecules (Nakagawa et al., 2004) to the cytosol thereby triggering Nlrp3 activation. Similarly, Staphylococcus aureus hemolysins ( $\alpha$ and $\beta$ ) trigger caspase- 1 activation in conjunction with released lipoproteins independently of P2X7R (Munoz-Planillo et al., 2009) again suggesting a role for bacterial toxins and hemolysins in fulfilling the second signal necessary for inflammasome activation.
Although studied extensively, the mechanism of Nlrp3 inflammasome activation has not been established so far. Efflux of $\mathrm{K}^{+}$has long been considered to be the mechanism for activation of this inflammasome (Petrilli et al., 2007). Activation of P2X7R results in rapid efflux of $\mathrm{K}^{+}$. However, P2X7R activation also influences the levels of other ions such as $\mathrm{Na}^{+}$and $\mathrm{Ca}^{2+}$ (Dietl and Volkl, 1994; Schilling et al., 1999; North, 2002). Another mechanism proposed suggests activation of Nlrp3 by cathepsin B released from ruptured lysosomes following phagocytosis of monosodium urate and alum (Dostert et al., 2008; Hornung et al., 2008). This was demonstrated by using cathepsin B inhibitors in cell culture. However, cathepsin B-deficient macrophages showed IL-1 $1 \beta$ levels comparable to wild-type macrophages in response to monosodium urate and alum (Dostert et al., 2009). Recently, reactive oxygen species (ROS) have also been proposed to be an upstream inducer of the Nlrp3 inflammasome complex (Zhou et al., 2010). However, the role of ROS is again controversial given the fact that cells from patients with chronic granulomatous disease or macrophages from gp91phox - deficient mice (that are defective in ROS generation) produced similar levels of inflammasome activation as their normal counterparts (Meissner et al., 2010; van de Veerdonk et al., 2010).

\section{CONCLUDING REMARKS}

Nlrp3 inflammasome is activated by a variety of microbial stimuli (Table 1). This variety obscures efforts to determine the upstream mechanism of Nlrp3 inflammasome activation. Although multiple mechanisms have been proposed for Nlrp3

Table 1 | Microbes and microbial components that induce Nlrp3 inflammasome activation.

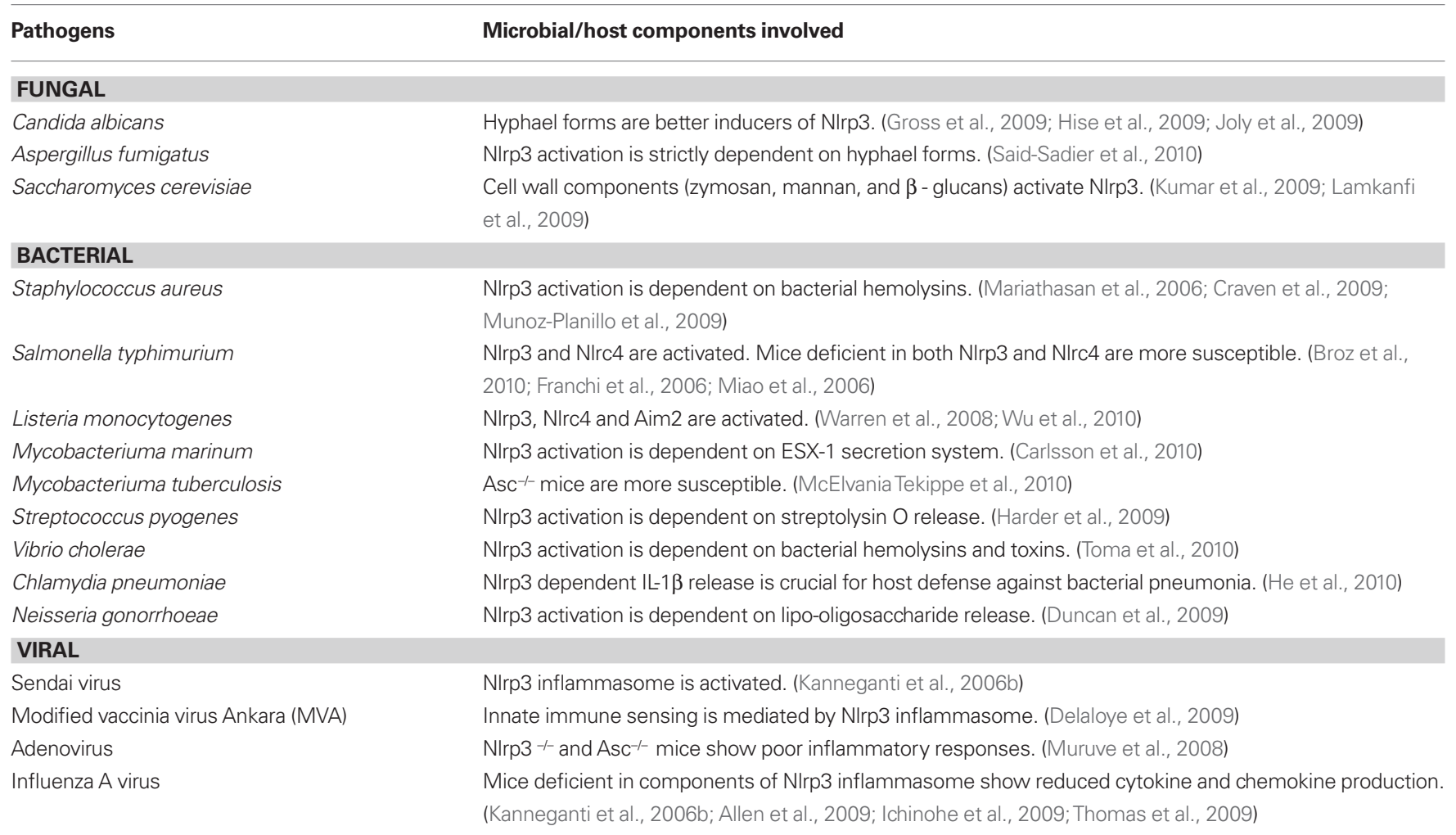




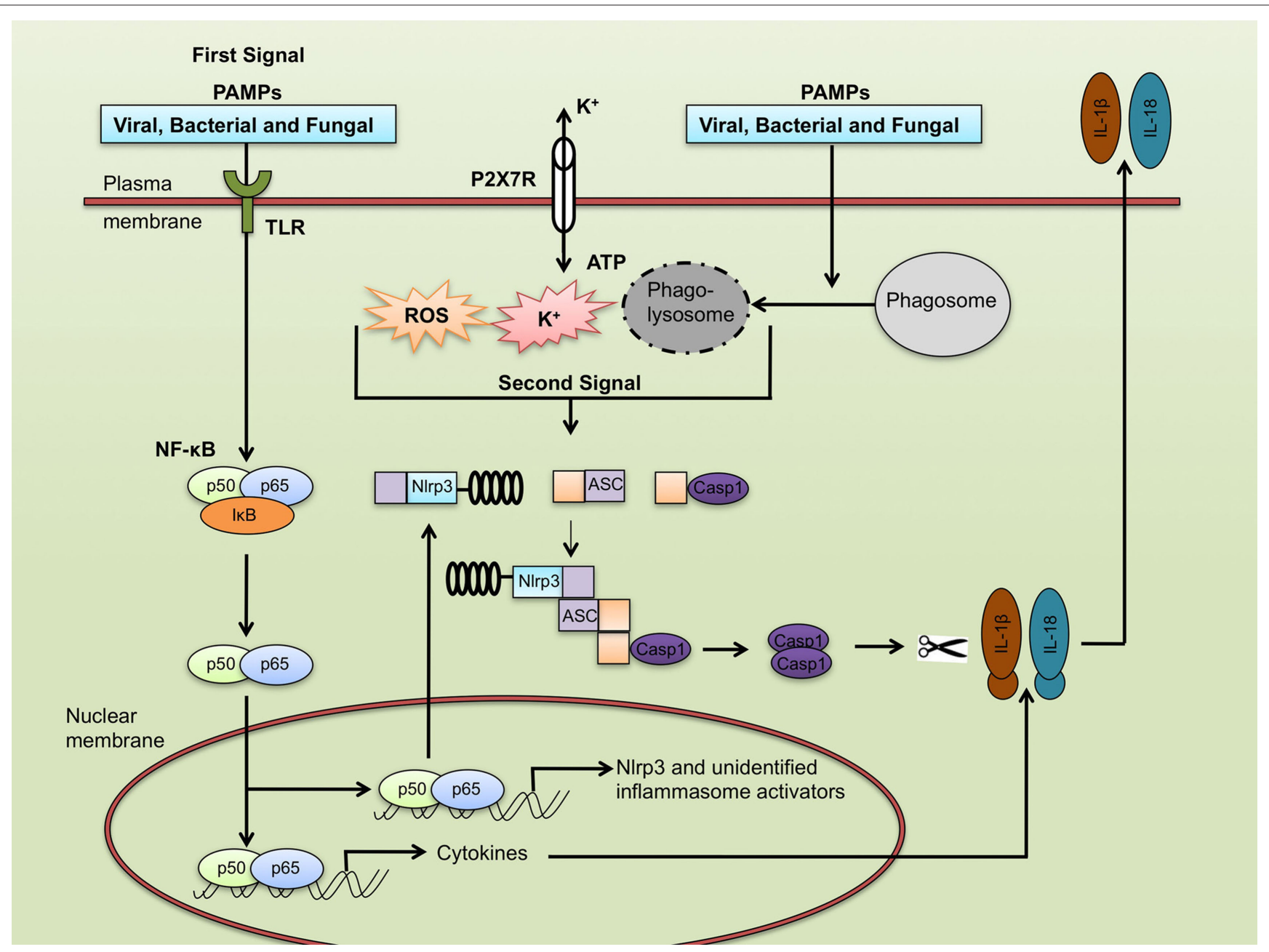

FIGURE 1 | Signaling mechanisms proposed for NIrp3 inflammasome activation. Extracellular and intracellular pathogen-associated molecular patterns (PAMPs) are sensed by toll-like receptors (TLRs; first signal) leading to $\mathrm{NF}-\kappa \mathrm{B}$ activation and transcription of cytokines. Additionally, NF- $\mathrm{KB}$ is also proposed to up-regulate Nlrp3 expression, which might be a limiting factor for inflammasome assembly. A wide range of pathogens trigger Nlrp3 inflammasome activation. The physiological insults resulting from exposure to these PAMPs can be narrowed down to a few mechanisms that drive NIrp3 activation. These mechanisms include $\mathrm{K}^{+}$efflux, lysosomal damage and reactive oxygen species (ROS) production (second signal). Activation of P2X7R by ATP results in membrane pores that allow $\mathrm{K}^{+}$efflux and entry of extracellular factors into the cytoplasm resulting in Nlrp3 activation. Phagocytosis of certain pathogenic microbes leads to rupture of lysosomes thereby releasing cathepsin $B$ into the cytoplasm and causing NIrp3 activation. Generation of ROS downstream of microbial infection has also been proposed to trigger Nlrp3. Nlrp3 inflammasome assembly consisting of the adaptor molecule Asc and pro-caspase- 1 leads to caspase-1 activation, which results in processing and secretion of cytokines IL-1 $\beta$ and IL-18. inflammasome activation (Figure 1), still no clearly defined consensus has emerged yet. It is highly probable that the different proposed mechanisms of Nlrp3 activation are not mutually exclusive and some common intersecting points exist between these various pathways. Future studies are likely to shed more light on this aspect besides deciphering the novel roles for Nlrp3 inflammasome.

\section{REFERENCES}

Allen, I. C., Scull, M. A., Moore, C. B., Holl, E. K., McElvania-TeKippe, E., Taxman, D. J., Guthrie, E. H., Pickles, R. J., and Ting,J.P. (2009). The NLRP3 inflammasome mediates in vivo innate immunity to influenza A virus through recognition of viral RNA. Immunity 30, 556-565.
Bauernfeind, F. G., Horvath, G., Stutz, A., Alnemri, E. S., MacDonald, K., Speert, D., Fernandes-Alnemri, T., Wu, J., Monks, B. G., Fitzgerald, K. A., Hornung, V., and Latz, E. (2009). Cutting edge: NF-kappaB activating pattern recognition and cytokine receptors license NLRP3 inflamma-

\section{ACKNOWLEDGMENTS}

We apologize to the numerous investigators whose papers could not be cited because of space limitations. This work was supported by National Institute of Health grants (AR056296 and AI088177) and a NIAMS Centers of Excellence for Influenza Research and Surveillance (CEIRS) grant to Thirumala-Devi Kanneganti and by the American Lebanese Syrian Associated Charities (ALSAC).

some activation by regulating NLRP3 expression. J. Immunol. 183, 787-791.

Boyden, E. D., and Dietrich, W. F. (2006)

Nalplb controls mouse macrophage susceptibility to anthrax lethal toxin. Nat. Genet. 38, 240-244.

Broz, P., Newton, K., Lamkanfi, M. Mariathasan, S., Dixit, V. M., and
Monack, D. M. (2010). Redundant roles for inflammasome receptors NLRP3 and NLRC4 in host defense against Salmonella. J. Exp. Med. 207, 1745-1755.

Carlsson, F., Kim, J., Dumitru, C., Barck, K. H., Carano, R. A., Sun, M., Diehl, L., and Brown, E. J. (2010). Host- 
detrimental role of Esx-1-mediated inflammasome activation in mycobacterial infection. PLoS Pathog. 6, e1000895. doi: 10.1371/journal. ppat.1000895

Craven, R. R., Gao, X., Allen, I. C., Gris, D., Wardenburg, J. B., McElvaniaTekippe, E., Ting, J. P., and Duncan, J. A. (2009). Staphylococcus aureus $\alpha$-hemolysin activates the NLRP3inflammasome in human and mouse monocytic cells. PLoS ONE 4, e7446. doi: 10.1371/journal.pone.0007446

Creagh, E. M., and O'Neill, L. A. (2006). TLRs, NLRs and RLRs: a trinity of pathogen sensors that co-operate in innate immunity. Trends Immunol. 27, 352-357.

Delaloye, J., Roger, T., Steiner-Tardivel, Q. G., Le Roy, D., Knaup Reymond, M., Akira, S., Petrilli, V., Gomez, C. E., Perdiguero, B., Tschopp, J., Pantaleo, G., Esteban, M., and Calandra, T. (2009). Innate immune sensing of modified vaccinia virus Ankara (MVA) is mediated by TLR2-TLR6, MDA- 5 and the NALP3 inflammasome. PLoS Pathog. 5, e1000480. doi: 10.1371/journal. ppat. 1000480

Dietl, P., and Volkl, H. (1994). Maitotoxin activates a nonselective cation channel and stimulates Ca2+ entry in MDCK renal epithelial cells. Mol. Pharmacol. 45, 300-305.

Dostert, C., Guarda, G., Romero, J. F., Menu, P., Gross, O., Tardivel, A., Suva, M. L., Stehle, J. C., Kopf, M., Stamenkovic, I., Corradin, G., and Tschopp, J. (2009). Malarial hemozoin is a Nalp3 inflammasome activating danger signal. PLoS ONE4, e6510. doi: 10.1371/journal.pone.0006510

Dostert, C., Petrilli, V., Van Bruggen, R., Steele, C., Mossman, B. T., and Tschopp, J. (2008). Innate immune activation through Nalp3 inflammasome sensing of asbestos and silica. Science 320, 674-677.

Duncan, J. A., Gao, X., Huang, M. T., O'Connor, B. P., Thomas, C. E., Willingham, S. B., Bergstralh, D. T., Jarvis, G. A., Sparling, P. F., and Ting, J. P. (2009). Neisseria gonorrhoeae activates the proteinase cathepsin $\mathrm{B}$ to mediate the signaling activities of the NLRP3 and ASC-containing inflammasome. J. Immunol. 182, 6460-6469.

Franchi, L., Amer, A., Body-Malapel, M., Kanneganti, T. D., Ozoren, N., Jagirdar, R., Inohara, N., Vandenabeele, P., Bertin, J., Coyle, A., Grant, E. P., and Nunez, G. (2006). Cytosolic flagellin requires Ipaf for activation of caspase-1 and interleukin lbeta in Salmonella-infected macrophages. Nat. Immunol. 7, 576-582.

Franchi, L., Eigenbrod, T., and Nunez, G. (2009). Cutting edge: TNF-alpha mediates sensitization to ATP and silica via the NLRP3 inflammasome in the absence of microbial stimulation. J. Immunol. 183, 792-796.

Gross, O., Gewies, A., Finger, K., Schafer, M., Sparwasser, T., Peschel, C., Forster, I., and Ruland, J. (2006). Card9 controls a non-TLR signalling pathway for innate anti-fungal immunity. Nature 442, 651-656.

Gross, O., Poeck, H., Bscheider, M., Dostert, C., Hannesschlager, N., Endres, S., Hartmann, G., Tardivel, A., Schweighoffer, E., Tybulewicz, V., Mocsai, A., Tschopp, J., and Ruland, J. (2009). Syk kinase signalling couples to the Nlrp3 inflammasome for anti-fungal host defence. Nature 459, 433-436.

Harder, J., Franchi, L., Munoz-Planillo, R., Park, J. H., Reimer, T., and Nunez, G. (2009). Activation of the Nlrp3 inflammasome by Streptococcus pyogenes requires streptolysin $\mathrm{O}$ and NF-kappa B activation but proceeds independently of TLR signaling and $\mathrm{P} 2 \mathrm{X} 7$ receptor. J. Immunol. 183 , 5823-5829.

He, X., Mekasha, S., Mavrogiorgos, N., Fitzgerald, K. A., Lien, E., and Ingalls, R. R. (2010). Inflammation and fibrosis during Chlamydia pneumoniae infection is regulated by IL- 1 and the NLRP3/ASC inflammasome. $J$. Immunol. 184, 5743-5754.

Hise, A. G., Tomalka, J., Ganesan, S. Patel, K., Hall, B. A., Brown, G. D., and Fitzgerald, K. A. (2009). An essential role for the NLRP3 inflammasome in host defense against the human fungal pathogen Candida albicans. Cell Host Microbe 5, 487-497.

Hornung, V., Bauernfeind, F., Halle, A., Samstad, E. O., Kono, H., Rock, K. L., Fitzgerald, K. A., and Latz, E. (2008). Silica crystals and aluminum salts activate the NALP3 inflammasome through phagosomal destabilization. Nat. Immunol. 9, 847-856.

Hornung, V., and Latz, E. (2010). Intracellular DNA recognition. Nat. Rev. Immunol. 10, 123-130.

Ichinohe, T., Lee, H. K., Ogura, Y., Flavell, R., and Iwasaki, A. (2009). Inflammasome recognition of influenza virus is essential for adaptive immune responses. J. Exp. Med. 206, 79-87.

Ichinohe, T., Pang, I. K., and Iwasaki, A. (2010). Influenza virus activates inflammasomes via its intracellular M2 ion channel. Nat. Immunol. 11, 404-410.

Joly, S., Ma, N., Sadler, J. J., Soll, D. R. Cassel, S. L., and Sutterwala, F. S. (2009). Cutting edge: Candida albicans hyphae formation triggers activation of the Nlrp3 inflammasome. J. Immunol. 183, 3578-3581.

Kankkunen, P., Teirila, L., Rintahaka, J., Alenius, H., Wolff, H., and
Matikainen, S. (2010). (1,3)-betaglucans activate both dectin- 1 and NLRP3 inflammasome in human macrophages. J. Immunol. 184 6335-6342.

Kanneganti, T. D. (2010). Central roles of NLRs and inflammasomes in viral infection. Nat. Rev. Immunol. 10 688-698.

Kanneganti, T. D., Lamkanfi, M., and Nunez, G. (2007). Intracellular NODlike receptors in host defense and disease. Immunity 27, 549-559.

Kanneganti, T. D., Ozoren, N., BodyMalapel, M., Amer, A., Park, J. H. Franchi, L., Taraporewala, Z. F., Miller, D., Patton, J. T., Inohara, N., and Nunez, G. (2006a). Bacterial RNA and small antiviral compounds activate caspase-1 through cryopyrin/ Nalp3. Nature 440, 233-236.

Kanneganti, T. D., Body-Malapel, M. Amer, A., Park, J. H., Whitfield, J. Franchi, L., Whitfield, J., Barchet, W. Colonna, M., Vandenabeele, P., Bertin, J. Coyle, A., Grant, E. P., Akira, S., and Nunez, G. (2006b). Critical role for Cryopyrin/Nalp3 in activation of caspase-1 in response to viral infection and double-stranded RNA. J. Biol. Chem. 281, 36560-36568.

Kumar, H., Kumagai, Y., Tsuchida, T. Koenig, P. A., Satoh, T., Guo, Z., Jang, M. H., Saitoh, T., Akira, S., and Kawai, T. (2009). Involvement of the NLRP3 inflammasome in innate and humoral adaptive immune responses to fungal beta-glucan. J. Immunol. 183 , 8061-8067.

Lamkanfi, M., and Kanneganti, T. D. (2010). Nlrp3: an immune sensor of cellular stress and infection. Int. J. Biochem. Cell Biol. 42, 792-795.

Lamkanfi, M., Malireddi, R. K., and Kanneganti, T. D. (2009). Fungal zymosan and mannan activate the cryopyrin inflammasome. J. Biol. Chem. 284, 20574-20581.

Lo, H. J., Kohler, J. R., DiDomenico, B. Loebenberg, D., Cacciapuoti, A., and Fink, G. R. (1997). Nonfilamentous $C$. albicans mutants are avirulent. Cell 90 939-949.

Mariathasan, S., Weiss, D. S., Newton, K., McBride, J., O’Rourke, K., RooseGirma, M., Lee, W. P., Weinrauch, Y., Monack, D. M., and Dixit, V. M. (2006). Cryopyrin activates the inflammasome in response to toxins and ATP. Nature 440, 228-232.

McElvania Tekippe, E., Allen, I. C., Hulseberg, P. D., Sullivan, J. T., McCann,J.R., Sandor, M., Braunstein, M., and Ting, J. P. (2010). Granuloma formation and host defense in chronic Mycobacterium tuberculosis infection requires PYCARD/ASC but not NLRP3 or caspase-1. PLoS ONE 5, e12320. doi: 10.1371/journal. pone. 0012320
Meissner, F., Seger, R. A., Moshous, D., Fischer, A., Reichenbach, J., and Zychlinsky, A. (2010). Inflammasome activation in NADPH oxidase defective mononuclear phagocytes from patients with chronic granulomatous disease. Blood 116, 1570-1573.

Mencacci, A., Bacci, A., Cenci, E., Montagnoli, C., Fiorucci, S., Casagrande, A., Flavell, R. A., Bistoni, F., and Romani, L. (2000). Interleukin 18 restores defective Thl immunity to Candida albicans in caspase 1-deficient mice. Infect. Immun. 68, 5126-5131.

Miao, E.A.,Alpuche-Aranda, C. M., Dors, M., Clark, A. E., Bader, M. W., Miller, S. I., and Aderem, A. (2006). Cytoplasmic flagellin activates caspase- 1 and secretion of interleukin 1beta via Ipaf. Nat. Immunol. 7, 569-575.

Munoz-Planillo, R., Franchi, L., Miller, L. S., and Nunez, G. (2009). A critical role for hemolysins and bacterial lipoproteins in Staphylococcus aureus-induced activation of the Nlrp3 inflammasome. J. Immunol. 183, 3942-3948.

Muruve, D. A., Petrilli, V., Zaiss, A. K., White, L. R., Clark, S. A., Ross, P. J., Parks, R. J., and Tschopp, J. (2008). The inflammasome recognizes cytosolic microbial and host DNA and triggers an innate immune response. Nature 452, 103-107.

Nakagawa, I., Amano, A., Mizushima, N., Yamamoto, A., Yamaguchi, H., Kamimoto, T., Nara, A., Funao, J. Nakata, M., Tsuda, K., Hamada, S., and Yoshimori, T. (2004). Autophagy defends cells against invading group A Streptococcus. Science 306, 1037-1040.

North, R. A. (2002). Molecular physiology of P2X receptors. Physiol. Rev. 82, 1013-1067.

Palsson-McDermott, E. M., and O’Neill, L.A. (2007). Building an immune system from nine domains. Biochem. Soc. Trans. 35, 1437-1444.

Petrilli, V., Papin, S., Dostert, C., Mayor, A., Martinon, F., and Tschopp, J. (2007). Activation of the NALP3 inflammasome is triggered by low intracellular potassium concentration. Cell Death Differ. 14, 1583-1589.

Poeck, H., and Ruland, J. (2010). SYK kinase signaling and the NLRP3 inflammasome in antifungal immunity. J. Mol. Med. 88, 745-752.

Romani, L. (2004). Immunity to fungal infections. Nat. Rev. Immunol. 4 , $1-23$

Said-Sadier, N., Padilla, E., Langsley, G. and Ojcius, D. M. (2010). Aspergillus fumigatus stimulates the NLRP3 inflammasome through a pathway requiring ROS production and the Syk tyrosine kinase. PLoS ONE 5, e10008. doi: 10.1371/journal. pone. 0010008

Schilling, W. P., Sinkins, W. G., and Estacion, M. (1999). Maitotoxin 
activates a nonselective cation channel and a P2Z/P2X(7)-like cytolytic pore in human skin fibroblasts. Am. J. Physiol. 277, C755-C765.

Thomas, P. G., Dash, P., Aldridge, J. R. Jr., Ellebedy, A. H., Reynolds, C., Funk, A. J., Martin, W. J., Lamkanfi, M., Webby, R. J., Boyd, K. L., Doherty, P. C., and Kanneganti, T. D. (2009). The intracellular sensor NLRP3 mediates key innate and healing responses to influenza A virus via the regulation of caspase-1. Immunity 30, 566-575.

Toma, C., Higa, N., Koizumi, Y., Nakasone, N., Ogura, Y., McCoy, A. J., Franchi, L., Uematsu, S., Sagara, J., Taniguchi, S., Tsutsui,H.,Akira, S., Tschopp, J., Nunez, G., and Suzuki, T. (2010). Pathogenic Vibrio activate NLRP3 inflammasome via cytotoxins and TLR/nucleotidebinding oligomerization domainmediated NF-kappa B signaling. J. Immunol. 184, 5287-5297.

Unterholzner, L., Keating, S. E., Baran, M., Horan, K. A., Jensen, S. B., Sharma, S.,
Sirois, C. M., Jin, T., Latz, E., Xiao, T. S., Fitzgerald, K.A., Paludan, S. R., and Bowie, A. G. (2010). IFI16 is an innate immune sensor for intracellular DNA. Nat. Immunol. 11, 997-1004.

van deVeerdonk, F.L., Joosten,L.A., Devesa, I., Mora-Montes, H. M., Kanneganti, T. D., Dinarello, C. A., van der Meer, J. W., Gow, N.A., Kullberg, B. J., and Netea, M. G. (2009). Bypassing pathogen-induced inflammasome activation for the regulation of interleukin-1beta production by the fungal pathogen Candida albicans. J. Infect. Dis. 199, 1087-1096.

van de Veerdonk, F. L., Smeekens, S. P., Joosten, L. A., Kullberg, B. J., Dinarello, C. A., van der Meer, J. W., and Netea, M.G. (2010). Reactive oxygen speciesindependent activation of the IL-1beta inflammasome in cells from patients with chronic granulomatous disease. Proc. Natl. Acad. Sci. U.S.A. 107, 3030-3033.

Vonk, A. G., Netea, M. G., van Krieken, J. H., Iwakura, Y., van der Meer, J. W., and Kullberg, B. J. (2006). Endogenous interleukin (IL)-1 alpha and IL-1 beta are crucial for host defense against disseminated candidiasis. J. Infect. Dis. 193, 1419-1426.

Warren, S.E., Mao, D. P., Rodriguez, A. E., Miao, E. A., and Aderem, A. (2008) Multiple Nod-like receptors activate caspase 1 during Listeria monocytogenes infection. J. Immunol. 180, 7558-7564.

Wu, J., Fernandes-Alnemri, T., and Alnemri, E. S. (2010). Involvement of the AIM2, NLRC4, and NLRP3 inflammasomes in caspase-1 activation by Listeria monocytogenes. J. Clin. Immunol. 30, 693-702.

Zhou, R. B., Tardivel,A., Thorens, B., Choi, I., and Tschopp, J. (2010). Thioredoxininteracting protein links oxidative stress to inflammasome activation. Nat. Immunol. 11, 136-140.

Conflict of Interest Statement: The authors declare that the research was conducted in the absence of any commercial or financial relationships that could be construed as a potential conflict of interest.

Received: 15 November 2010; paper pending published:06 December 2010; accepted: 19 January 2011; published online: 02 February 2011.

Citation: Anand PK, Subbarao Malireddi RK and Kanneganti T-D (2011) Role of the Nlrp3 inflammasome in microbia infection. Front. Microbio. 2:12. doi: 10.3389/fmicb.2011.00012

This article was submitted to Frontiers in Cellular and Infection Microbiology, a specialty of Frontiers in Microbiology.

Copyright (C) 2011 Anand, Subbarao Malireddi and Kanneganti. This is an open-access article subject to an exclusive license agreement between the authors and Frontiers Media SA, which permits unrestricted use, distribution, and reproduction in any medium, provided the original authors and source are credited. 